\title{
Effect of Middle Ear Gelfoam on Hearing and Healing Process after Tympanoplasty: A Prospective Randomized Case-Control Study
}

\author{
Jae Sang Han ${ }^{1}$, Jung-Ju Han², Yahya AlAhmari², Jung-Mee Park ${ }^{2}$, So-Young Park ${ }^{3}$, and \\ Shi Nae Park ${ }^{4}$ \\ ${ }^{1}$ Catholic University of Korea \\ ${ }^{2}$ The Catholic University of Korea, College of Medicine \\ ${ }^{3}$ Department of Otolaryngology-Head and Neck Surgery, The Catholic University of Korea \\ College of Medicine \\ ${ }^{4}$ Seoul St. Mary's hospital, the catholic university of college of medicine , \\ Otolaryngology-Head and Neck Surgery.
}

May 12, 2020

\begin{abstract}
Introduction: This prospective randomized case-control study was performed to compare the surgical outcomes of our swing-door overlay tympanoplasty with or without absorbable gelatine sponge (AGS, gelfoam) packing in the middle ear cavity, according to the surgical procedure. Subjects and Methods: Fifty-seven patients who underwent swing-door overlay tympanoplasty by a single surgeon were enrolled in the study. The data of 30 patients of the gelfoam-packing group (GPG) and 27 patients of the non-gelfoam-packing group (NGPG) were prospectively collected and compared. Results: Closure of the tympanic membrane was found to be successful in all patients at postoperative 3 months evaluation. NGPG showed a statistically better healing process compared to GPG; earlier epithelialization and less fascia edema in NGPG than in GPG $(\mathrm{P}<0.05)$. The air-bone gap (ABG) measured at postoperative 1 and 2 months was smaller in NGPG than GPG, although there were no statistical differences. Conclusion: Swing-door overlay tympanoplasty showed good surgical outcomes in terms of graft uptake rate regardless of AGS packing. However, this study revealed earlier healing process and faster recovery of ABG in NGPG, thereby indicating that the gelfoam in the middle ear may interfere with both hearing recovery and the healing process of neodrum. Non-gelfoam packing in the middle ear cavity appeared to be superior to gelfoam packing in swing-door overlay tympanoplasty.
\end{abstract}

\section{INTRODUCTION}

Tympanoplasty is a common and well known surgical procedure in the otologic area. Numerous factors affecting the final surgical outcomes include the graft materials, causes of perforation, and age ${ }^{1}$. However, little attention has been paid to middle ear packing material(MEPM)s and their effects on the graft materials, ossicular changes, hearing, etc in the success of tympanoplasty. Absorbable gelatine sponge (AGS, gelfoam) was introduced by Correl and Wise as an absorbable haemostatic agent in 1945, andit has become the most commonly used MEMP in clinical practice. This material established its place as a scaffolding substance to support the grafting material and ossicular chains during tympanoplasty ${ }^{2}$.

Swing-door overlay tympanoplasty, which has been published recently with excellent surgical results, is a modified technique of classic overlay tympanoplasty ${ }^{3}$. In this surgical technique, clearly visible annulus plays a role as a splint and prevent falling of the graft material. It was conjectured that the tympanoplasty 
without gelfoam packing in the middle ear may facilitate the healing process of the neodrum as well as hearing recovery.

This prospective randomized case-control study was performed to compare the surgical outcomes of swingdoor overlay tympanoplasty with or without gelfoam packing in the middle ear in patients with chronic otitis media(COM), according to the surgical procedure.

\section{SUBJECTS AND METHODS}

\section{Subjects}

Fifty-seven patients who underwent swing-door overlay tympanoplasty by one surgeon (S.N.P) in the department of otorhinolaryngology-head and neck surgery of tertiary referral centre between June 2015 and May 2016 were enrolled in this study. Patients who had cholesteatoma and previous middle ear surgery history were excluded. They were randomly divided into the gelfoam-packing group(GPG) and the non-gelfoampacking group(NGPG). The data of 30 patients of GPG and 27 patients of NGPG were prospectively collected and compared. All patients visited the outpatient department every month for up to postoperative 3 months.

\section{Physical and Audiologic Evaluations}

Postoperative healing status of the neodrum with perforation,retraction, lateralization, or anterior wall blunting was considered as surgical failure, whereas complete healing of the neodrum without perforation, free mobile drum without atelectasis, and keeping the anteroinferior tympanomeatal recess angle almost acute without blunting as shown under a microscope were designated as the success of healing. Post-operative edema of the fascia and degree of neodrum epithelization were observed by a 0-degree otoendoscope (Karl Storz, Tuttlingen, Germany). With the group blinded, two otology specialists quantified the degree of edema and epithelization of the neodrum. Out of the total neodrum width, the epithelized area was scored as percent and the edema rate was measured in scores from 0 to 3 points; 0 as none, 1 as mild, 2 as moderate, and 3 as severe edema. Also, changes in the air-bone gap (ABG) were conducted with pure-tone audiometry (PTA) of $0.5,1,2$, and $4 \mathrm{kHz}$ for evaluating audiologic outcome.

\section{Surgical procedure}

All patients underwent swing-door overlay tympanoplasty ${ }^{3}$. Under general anaesthesia, the temporalis muscle facia harvested as usual. After reaching the meatus via a post-auricular skin incision, the posterior canal skin was incised circumferentially from 12 to 6 o'clock. A superior longitudinal incision was made to join the circumferential cut. The remnant of the tympanic membrane (TM) was excised and pathologic tissue in the middle ear cavity was removed. After irrigation, middle ear gelfoam packing was performed only in GPG.

The fascia graft was placed following the modified overlay technique, involving placing the fascia under the handle of the malleus (umbo)and elevated tympanomeatal flap but over the annulus. Lastly, firm furacin gauze packing over thebony tympanic sulcus and the external auditory canal was performed. At postoperative 1 month, the packing was completely removed.

\section{Statistical Analysis}

SPSS24.0 program for Windows (SPSS Inc., Chicago, IL) was used for statistical analysis. Data were expressed as mean, standard deviation, and percentage.Student's t-test and chi-square testwere used to compare the clinical characteristics of the patients and student's t-test was used to analyse the surgical outcomes. Differences were considered significant when the p-value was 0.05. 


\section{RESULTS}

\section{Clinical characteristics}

Patients were aged between 10 and 81 years with the mean age of 51.5 years, and there was no statistically significant difference in age $(p=0.480)$ and sex ratio $(p=0.514)$ between the two groups. The operation site was on the right in 25 patients $(43.9 \%)$ and on the left in 32 patients $(56.1 \%)$. The right side was more common in GPG, while the left side was more common in NGPG, thereby demonstrating a statistically significant difference $(p=0.041)$.

The locations of perforation in the TMalso showed no significant difference between the two groups $(p=0.725)$ and the mean preoperative perforation size of TM was $29.5 \%$ in GPG and $32.2 \%$ in NGPG $(p=0.702)$. The clinical characteristics of the enrolled patients of the two groups are presented and compared in Table 1.

\section{Physical Evaluations}

There was no difference in the graft success rate between GPG and NGPG, since all the patients showed successful graft uptake at postoperative 3 month evaluation(Figure 1).During the follow-up period, none of the patients of this study developed postoperative otorrhea, lateralization of neodrum, anterior wall blunting, facial palsy, profound hearing loss or other problems.

However, NGPG showed the statistically significant faster healing process compared to GPG. The higher neodrum epithelization percent was observed in NPG during the follow up period, with significant differences in postoperative 1-month(68.00 $\pm 16.48 \%$ in GPG and $76.30 \pm 13.34 \%$ in NGPG, $p=0.043)$ and 2-month evaluation $(94.67 \pm 6.87 \%$ in GPG and $99.26 \pm 2.67 \%$ in NGPG, $p=0.007)$. Also,neodrum edemascorewas significantly lower in NGPG at 1-month(1.23 \pm 0.91 in GPG $0.74 \pm 0.62$ in NGPG, $p=0.044)$ and 2 -month $(0.19 \pm 0.40$ in GPG and $0.04 \pm 0.21$ in NGPG, $p=0.085$ )evaluations. Complete epithelization and amd loss of edema were observed in both groups at the 3-month visit. (Figure 2)

\section{Audiologic Evaluations}

A comparison of the preoperative and final hearing measured at postoperative 3 months between GPG and NGPG did not show any differences $(p>0.05)$. Although there were no statistical differences, the ABG measured at1-month (24.94 $\pm 11.38 \mathrm{~dB}$ in GPG and 20.90 $\pm 9.99 \mathrm{~dB}$ in NGPG, $p=0.161)$ and 2-months $(22.36 \pm 14.37 \mathrm{~dB}$ in GPG and $15.80 \pm 11.43$ in NGPG, $p=0.144)$ after surgery was smaller in NGPG than in GPG, thereby indicating an earlier hearing recovery in NGPG compared with GPG (Figure3).

\section{DISCUSSION}

AGS has been used as a MEMP during otologic surgery for the past 60 years with the introduction of Gelfoam by Zollner and Wullstein ${ }^{4}$. This absorbable material serves to support TM grafts and ossicular chain prosthetic devices during the postoperative healing period. It has been known that AGS plays a role in enhancing epithelialization of the graft material and probably functions as an adherence promoter of the graft to the remnant of the $\mathrm{TM}^{2}$. However, there are exists some controversies regarding its use. AGS has been reported to induce an inflammatory reaction, causing fibrosis and adhesions within the middle ear, which leads to conductive hearing impairment due tothe adherence of the grafted TM to the promontory or fixation of the ossicular-chains ${ }^{5}$. Since postoperative inflammation and fibrosis in the middle ear cavity have been known as one of the reasons forthe unsuccessful hearing results after tympanoplasty, several materials have been explored to replace $\mathrm{AGS}^{2,6-10}$.

Polyurethane foam(PUF) was marketed as a MEPMand synthetic biodegradable foam. A histologic study by Dogru et al. ${ }^{11}$ compared short-term and long-term appearances of middle ears packed with either AGS 
or PUF in a traumatic model of the rat with middle ear packing. In the reported study, the PUF induced mild inflammation and fibrosis in the middle ear in contrast to the severe inflammatory process and fibrosis associated with AGS packing. However, another study with an animal model of middle ear trauma and PUF or AGS packing showed a similar degree of inflammation and neo-osteogenesis in the middle ear with both the packingmaterials ${ }^{12}$. A recent experimental study comparingthe effects of AGS and another packing material, Otopore ${ }^{\mathrm{TM}}$ (Stryker, USA; Otopore group) in the middle ear cavity demonstrated less inflammation, adhesion, and new bone formation in Otopore ${ }^{\mathrm{TM}}$ packing group, despite the absence of substantiation about its long-term safety ${ }^{13}$. In a review article investigating 12 middle ear absorbable packing agents including gelfoam, Shen et al. ${ }^{14}$ reported that there exists no perfect agent for middle ear packinguntil date. In addition, theysuggestedthatnone of thepacking materialswould be associated with advantages related toan immediate improvementin hearing, shorteningthe operating time, reduction in thecost and patients' comfort, although there is a lack of clinical evidence.

There exist only a few clinical studies regarding middle ear packing materials. Most of the studies have dealt with animal models $5,7,8,10,11,13,15$, and only one comparative study has reported the effects ofMEMP on the outcomes of middle ear surgery in human ${ }^{14}$. Smith et al. ${ }^{16}$ reported better hearingresults of the hydroxylapatite/titanium bell partial ossicularreplacement prosthesis (PORP) without gelfoam compared with the conventionalPORP with gelfoam. However, the reportedstudy had a limitation in its rationale on theeffect of MEPM as the conditions were not controlled. Previous clinical studies without gelfoam during overlay tympanoplasty or ossiculoplasty demonstrated excellentsurgical results, which guided us to perform a more scientific and clinical study to demonstrate the effect of $\mathrm{MEPM}^{3,17}$. Our study is the first prospective randomized case-control study to investigatethe effects of middle ear packing using AGS in terms of surgical results and healing processes in humans. While the overall graft success rate was not affected by middle ear packing using AGS, the delayed epithelization of TM and more severe fascia edema were observed in GPG, thereby suggesting that AGS may interrupt the healing process of TM. In addition, larger postoperative ABG was observed in GPG for up to two months,although no significant difference was shown in the third month visit. This result suggests that AGS may remain in the middle ear for more than two months, similar to previous animal studies ${ }^{7,18,19}$. Therefore,based on our study results, surgical techniqueswithout middle ear packing can be recommended to reduce patient's discomfort caused by delayedhearing improvement and achieve a faster healing process.

Middle ear packing is essential for conventional underlay tympanoplasty to support the graft ${ }^{20}$. Therefore, even in underlay tympanoplasty, other surgical techniques without MEPM have been suggested. Yuasa et al. ${ }^{21}$ introduced simple underlay myringoplasty with fibrin glue in 1989 . They inserted a connective tissue through perforation using the underlay technique and fixed it with fibrin glue without middle ear packing. However, this method exhibited limited visibility into the middle ear and a relatively low overall initial success rate of $77.7 \%^{22}$. Another technique, inlay butterfly cartilage tympanoplastywithout middle ear packingwas introduced by Eavey et al. in $1998^{23}$. Theperforation closure rate was observed between 71 to $100 \%$, but this method has limitationsfor patients with large perforationbecause of the small remaining part of the TM which cannot support the cartilage on its own ${ }^{24,25}$.Previously, we have introduced the technique and surgical outcomes of a modified method for overlay tympanoplasty; swing-door overlay tympanoplasty. No MEPM was required for this technique and a high success rate of graftuptake(98.4\%) with satisfactory hearing results (postoperative ABG was closed to [?]20 dB in 86.9\%) was observed in the study. The advantage of this surgical method is that the swing door technique provides a better surgical view and makes it easier to perform surgery than conventional overlay tympanoplasty, and can be applied to all types of chronic otitis media regardless of the size of TM perforation ${ }^{3}$.

Given that the previous animal studies demonstratedfibrosis or inflammatory reactionin the middle ear cavity by AGS, our clinical study demonstratedthe negative effects of AGS in terms of healing processes of neodrum. Also, delayed hearing improvement appeared to be comprehensible. 


\section{CONCLUSION}

Swing-door overlay tympanoplasty showed good surgical outcomes in terms of graft uptake rate regardless of gelfoam packing. However, our prospective randomized controlled study showed earlier hearing improvement and faster healing process in NGPG, thereby indicating that the gelfoam in the middle ear may interfere with the healing process of neodrum and middle ear cavity. Consequently, it is proposed that surgical technique without AGS during middle ear surgery should be considered based on the advantages of the faster healing process and better hearing results.

\section{DISCLOSURE STATEMENT}

All authors have approved this manuscript, and there are no conflicts of interest to report.

\section{REFERENCES}

1. Tan HE, Santa Maria PL, Eikelboom RH, Anandacoomaraswamy KS, Atlas MD. Type I Tympanoplasty Meta-Analysis: A Single Variable Analysis. Otol Neurotol . 2016;37:838-846.

2. Hellstrom S, Salen B, Stenfors LE. Absorbable gelatin sponge (Gelfoam) in otosurgery: one cause of undesirable postoperative results? Acta Otolaryngol . 1983;96:269-275.

3. Park SY, Lee HJ, Shim MJ, Kim DK, Suh BD, Park SN. Swing-Door Overlay Tympanoplasty: Surgical Technique and Outcomes. Clin Exp Otorhinolaryngol . 2018;11:186-191.

4. Gisselsson L. Improvement of hearing by surgical repair of the drum and ossicular chain; report of five cases operated on by the method of Zollner and Wullstein. Acta Otolaryngol Suppl . 1954;118:100-108.

5. McGhee MA, Dornhoffer JL. The effect of gelfilm in the prevention of fibrosis in the middle ear of the animal model. Am J Otol . 1999;20:712-716.

6. Angeli S, Connell S, Gibson B, Ozdek A, McElveen JT, Jr., Van De Water TR. Injectable form of crosslinked hyaluronan is effective for middle ear wound healing. Ann Otol Rhinol Laryngol . 2007;116:667-673.

7. Joseph RB. The effect of absorbable gelatin sponge preparations and other agents on scar formation in the dog's middle ear. An experimental histopathologic study. Laryngoscope . 1962;72:1528-1548.

8. Laurent C, Hellstrom S, Stenfors LE. Hyaluronic acid reduces connective tissue formation in middle ears filled with absorbable gelatin sponge: an experimental study. Am J Otolaryngol . 1986;7:181-186.

9. Liening DA, Lundy L, Silberberg B, Finstuen K. A comparison of the biocompatibility of three absorbable hemostatic agents in the rat middle ear. Otolaryngol Head Neck Surg . 1997;116:454-457.

10. Lipan MJ, Alava I, Abi-Hachem R, Vernon S, Van De Water TR, Angeli SI. Middle ear packing: comparison of materials in an animal model of mucosal trauma. Otolaryngol Head Neck Surg . 2011;144:763769.

11. Dogru S, Haholu A, Gungor A, et al. Histologic analysis of the effects of three different support materials within rat middle ear. Otolaryngol Head Neck Surg . 2009;140:177-182.

12. Perez E, Hachem RA, Carlton D, et al. Comparison of packing material in an animal model of middle ear trauma. Am J Otolaryngol . 2016;37:323-329.

13. Deniz B, Oguzhan KR, Erdem O, Hasan S, Fuat YY, Muge O. The effects of different packing materials on healing and hearing after trauma to middle ear mucosa, an experimental study in rats. Am J Otolaryngol . 2019;40:347-352. 
14. Shen Y, Teh BM, Friedland PL, Eikelboom RH, Atlas MD. To pack or not to pack? A contemporary review of middle ear packing agents.Laryngoscope . 2011;121:1040-1048.

15. Goncalves S, Chiossone-Kerdel JA, Bianco AS, Ercolino JM, Hernandez-Rojas J. Effect of absorbable gelatin sponge in the middle ear: in vitro and in vivo animal model. Acta Otolaryngol . 2015;135:14-25.

16. Smith J, Gardner E, Dornhoffer JL. Hearing results with a hydroxylapatite/titanium bell partial ossicular replacement prosthesis. Laryngoscope . 2002;112:1796-1799.

17. Kong JS, Jeong CY, Shim MJ, Kim WJ, Yeo SW, Park SN. Comparative study of new autologous material, bone-cartilage composite graft, for ossiculoplasty with Polycel((r)) and Titanium. Clin Otolaryngol . 2018;43:434-439.

18. Doyle-Kelly W. Behaviour of absorbable gelatine sponge in the animal middle ear. J Laryngol Otol . 1961;75:152-166.

19. Withers BT, Nail BM, Jr., Alford BR. The effects of burying epithelium in the middle ear of animals: clinical implications. Trans Am Acad Ophthalmol Otolaryngol . 1960;64:863-871.

20. Rizer FM. Overlay versus underlay tympanoplasty. Part I: historical review of the literature. Laryngoscope . 1997;107:1-25.

21. Yuasa R, Saijo S, Tomioka Y, et al. Office closure of eardrum perforation with fibrin glue. Otolaryngol Head Neck Surg (Tokyo) . 1989;61:1117-1122.

22. Sakagami M, Yuasa R, Yuasa Y. Simple underlay myringoplasty. J Laryngol Otol . 2007;121:840-844.

23. Eavey RD. Inlay tympanoplasty: cartilage butterfly technique.Laryngoscope . 1998;108:657-661.

24. Jumaily M, Franco J, Gallogly JA, et al. Butterfly cartilage tympanoplasty outcomes: A singleinstitution experience and literature review. Am J Otolaryngol . 2018;39:396-400.

25. Kim MB, Park JA, Suh MJ, Song CI. Comparison of clinical outcomes between butterfly inlay cartilage tympanoplasty and conventional underlay cartilage tympanoplasty. Auris Nasus Larynx . 2019;46:167-171.

Figure legends

Figure 1. Serial oto-endoscopic findings of pre-and post-operative tympanic membranes.

All included patients showed successful graft uptake at postoperative 3 months. However, NGPG showed statistically significant earlier epithelializationand less edematous fascia compared to GPG at postoperative 1-and 2-months $(p<0.05)$. (GPG; gelfoam-packing group, NGPG; non-gelfoam-packing group.)

Figure 2. Changes in the postoperative graft epithelization and graft edema score.

(A) The percentage of epithelization was measured by two otologic specialists based on the ratio of the epithelized neodrum in the entire grafted eardrum.Significantly higher epithelialization percentages wereobserved in NGPG compared to GPG at1-and 2-months visits $(p<0.05)$. (B) The severity of edema of the grafted fascia was quantified by two otologic specialists; none $=0$, mild $=1$, moderate $=2$, and severe $=3$. The edema score of the graft in NGPG was lower in NGPG than in GPG at postoperative 1- and 2-months visits, thereby indicatinga better healing process in the NGPG $(p<0.05)$. (GPG; gelfoam-packing group, NGPG; non-gelfoam-packing group. Error bars indicate standard deviations. ${ }^{*} P<0.05$. Student's t-test.)

Figure 3. Comparison of the air-bone gaps between GPG and NGPG.

Air-bone gap(ABG)s were measured with average pure tone hearing thresholds at 0.5, 1, 2, and 4 $\mathrm{kHz}$.Although there was no statistical difference $(p>0.05)$, the mean values showed lower ABG in NGPGat 1- and 2-months visits, thereby indicatinga faster hearing improvement in NGPG.(dB; decibel, GPG; gelfoampacking group, NGPG; non-gelfoam-packing group. Error bars indicate standard deviations.Student's t-test.)

Hosted file 
Gelfoam_Table.docx available at https://authorea.com/users/321048/articles/450381-effectof-middle-ear-gelfoam-on-hearing-and-healing-process-after-tympanoplasty-a-prospectiverandomized-case-control-study
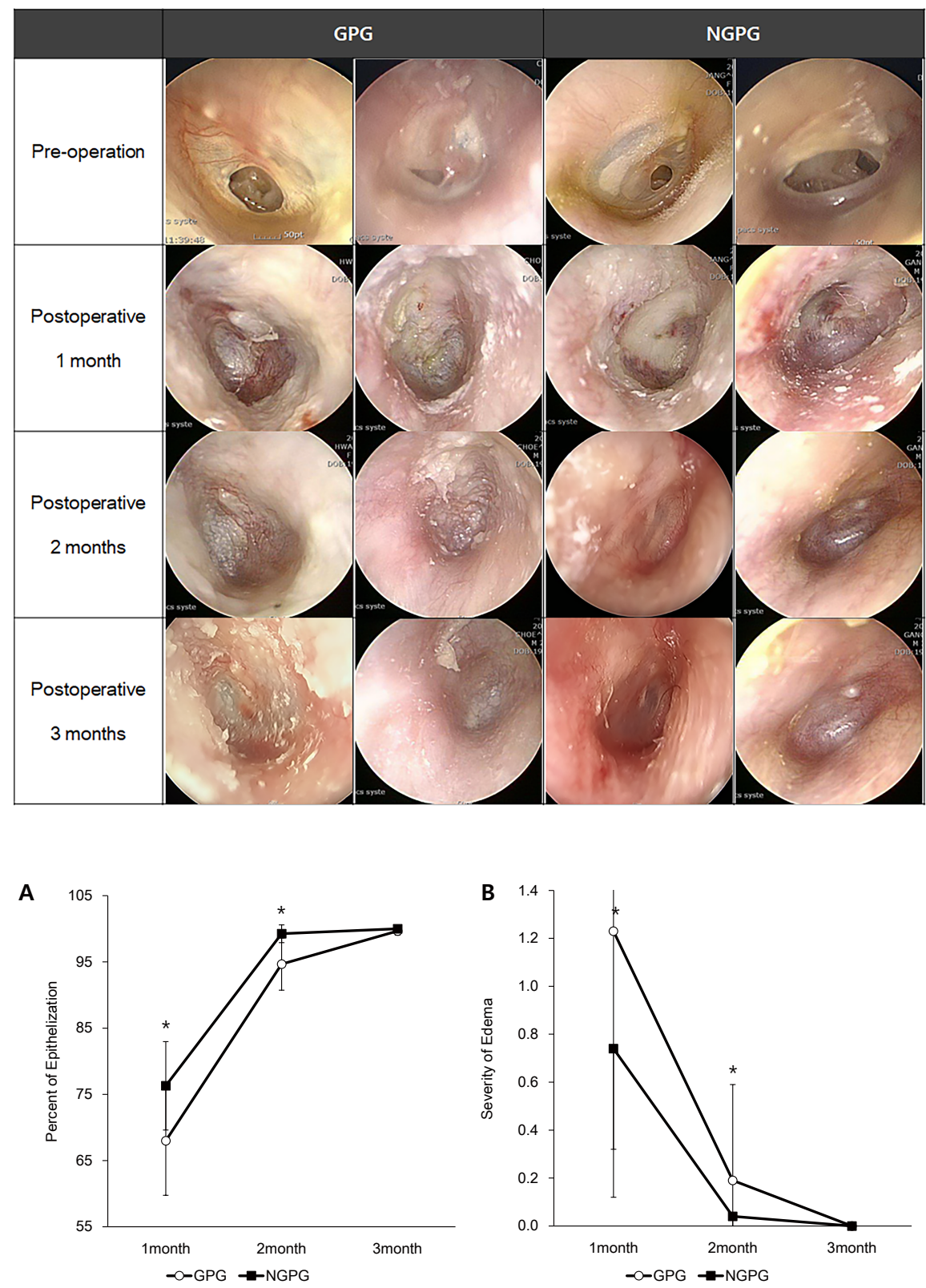


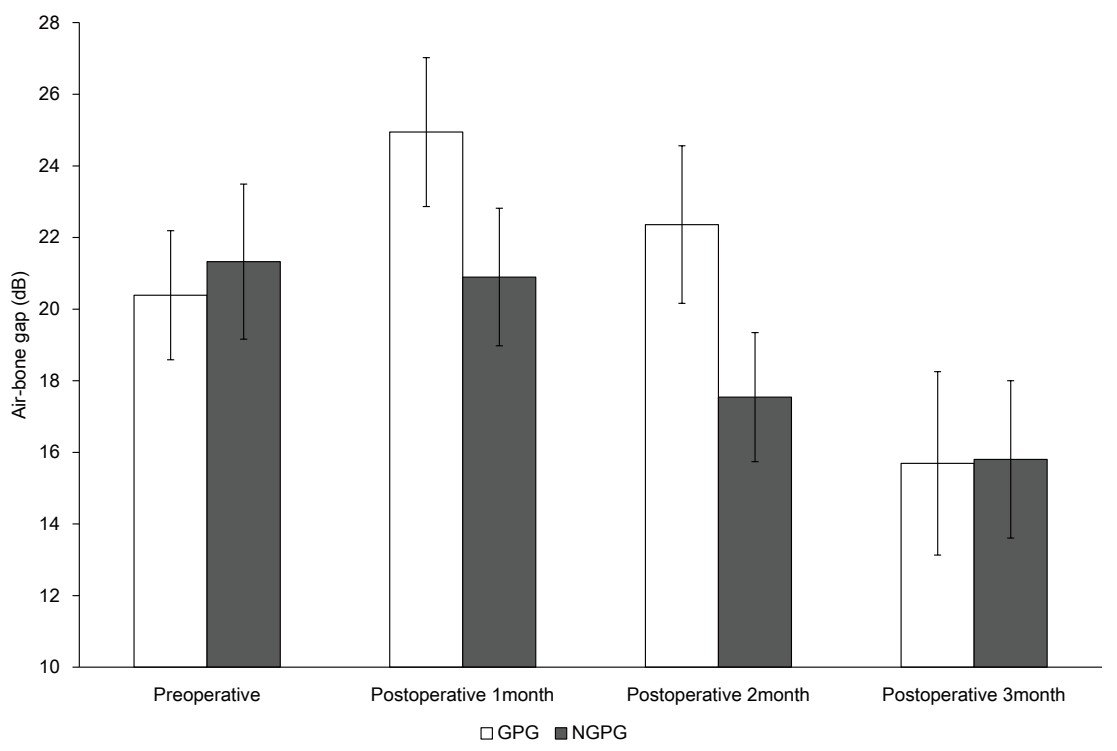

